\title{
TFIIIC Subunit Gene
}

National Cancer Institute

\section{Source}

National Cancer Institute. TFIIIC Subunit Gene. NCI Thesaurus. Code C20663.

RNA polymerases are unable to initiate RNA synthesis in the absence of general transcription factors (GT Fs). GT Fs assemble in a complex on the DNA promoter and recruit the RNA polymerase. TFIIIC Subunit Genes encode the TFIIIC protein complex that is essential for RNA polymerase III to make a number of small nuclear and cytoplasmic RNAs, including 5S RNA, tRNA, and adenovirus-associated (VA) RNA of both cellular and viral origin. The TFIIIC complex interacts with TFIIIB in the recruitment of RNA polymerase III. Transcription by RNA polymerase III is enhanced during viral infection by the expression of immediate early proteins of adenovirus and pseudorabies virus. (from OMIM 604888) 